\title{
Numerical Investigation of Shell and Tube Heat Exchanger Using $\mathrm{Al}_{2} \mathrm{O}_{3}$ Nanofluid
}

\author{
Akshay Kumar Surana ${ }^{1}$, K. John Samuel ${ }^{1}$, Shrutesh Harshit ${ }^{1}$, Ujjwal Kumar ${ }^{1}$, R. Thundil Karuppa Raj ${ }^{1 *}$ \\ School of Mechanical Engineering, VIT University, Vellore-632014, Tamil Nadu India. \\ E-mail: *thundilr@gmail.com
}

Received 22 October 2016, Revised 24 January 2017, Accepted 10 Februrary 2017

\begin{abstract}
This paper presents the effect of number of tubes, unequal baffle spacing and tube diameter on heat transfer and pressure drop characteristics of a typical shell and tube type heat exchanger. Upon geometrical optimization, the second phase of this research work aims at studying the influence of $\mathrm{Al}_{2} \mathrm{O}_{3}$ nanofluid of $0.5 \%, 0.75 \%, 1 \%, 1.25 \%$ and $1.5 \%$ concentrations by admitting water along the tubes and $\mathrm{Al}_{2} \mathrm{O}_{3}$ nanofluid along the shell side. The shell and tube heat exchangers of various geometrical configurations are modeled using SOLIDWORKS 2015. The heat transfer and fluid flow characteristics through the heat exchanger are obtained by solving the governing equations namely continuity, momentum and energy equations using ANSYS CFX 15 CFD code. Temperature, pressure contours and velocity streamlines along the mid-plane of the shell and tube heat exchanger are obtained for various geometrical configurations and for different volume concentration of nanofluid. The heat transfer coefficient and the pressure drop for various volume fraction concentrations of the nanofluid are plotted. The use of nanofluid resulted in increase of both the pressure drop and heat transfer coefficient. The heat transfer coefficient at $1.25 \%$ volume concentration of nanofluid is found to be the optimum value.
\end{abstract}

Keywords: Shell and tube heat exchanger; CFD; nanofluid; tube diameter; tube number; baffle spacing.

\section{Introduction}

The demand for energy is increasing but the reserves of energy are limited. There is an urgent need for the conservation of energy. One way is to reduce the losses encountered in different types of thermal devices such as heat exchangers and thereby, increasing the economics of energy used which can be a potential solution to this problem.

The most common type of heat exchangers used in chemical processing plants and oil refineries are the shell and tube heat exchangers. It consists of a large pressure vessel called the shell and a number of tubes collectively termed as a tube bundle. The heat exchange between two fluids at different temperatures takes place as one type of fluid flows within the tubes and the other around the tubes. The main reason for efficient usage of this type of heat exchanger is due to their high coefficient of heat transfer and easy operation and maintenance. Pressure drop and heat transfer coefficient are the two important parameters taken in to consideration for evaluating the performance of shell and tube type heat exchanger. In general high heat transfer coefficient and minimum pressure drop is desirable for heat exchangers. A heat exchanger with high heat transfer coefficient and low pressure drop is desirable. A higher heat transfer coefficient indicates higher heat transfer rate and a lower pressure drop indicates lower pumping power. There are numerous geometrical parameters which affects the performance of shell and tube heat exchanger namely pitch of the tube, baffle pitch, tube diameter, number of tubes, number of baffles, type of baffles, type of baffle spacing, baffle cut and fluids used etc.

In general all the shell and tube type heat exchangers are built taking TEMA standards in to consideration, which publishes its standards and design recommendations, the latest being published in 2007 (9th edition) [1].

The effect of number of baffles and mass flow rate on fluid flow in shell side has been studied by Ozden and Tari [2]. The heat transfer coefficient is found to vary in direct proportion to the mass flow rate and indirectly proportional to number of baffles. The pressure drop across the shell side is found to increase if baffle numbers and mass flow rate are increased. Rad et al [3] investigated the influence of using porous media in a shell and tube heat exchanger. When the porous media is located at the center of the tubes, the pressure drop prevailed over the heat transfer rate and when connected to the inner walls of the tubes, the increase in heat transfer rate is found to be much higher than the increase in the pressure drop. An optimum level of porosity (60\%) and porous radius ratio $(0.6)$ is obtained when the porous medium is used in the shell side. In this case, the pressure drop and heat transfer are compromised. The influence of various geometrical parameters such as pitch of the tube, diameter of shell and tube, tube length, number of tubes, diameter of the nozzle and tube arrangements on the heat transfer in a shell and tube heat exchanger without any baffles is studied by Kim and Aicher [4]. The experiment consisted of heat exchangers with 32 different types configurations. Prithiviraj and Andrews [5] used a 3-D, fully implicit scheme to simulate the flow behavior across the shell side of a shell and tube type heat exchanger. The tubes are modeled in a three dimensional heat exchanger using distributed resistance consisting of surface permeabilities and volumetric porosities. The experiment showed that the pressure drop and heat transfer coefficient increased on increasing the mass flow rate and the effect of leakage is more on the pressure drop than the heat transfer. The variation in pressure drop 
and heat transfer characteristics for three different type of heat exchangers designed with one segmented baffles, mono layer helical baffles and double layer helical baffles respectively is studied by Lei et al [6]. When compared with single segmental baffles the single helical baffles $75 \%$ heat transfer capacity but only $50 \%$ of the pressure drop. From the work it is reported that the heat exchanger with double layer helical baffles is effective in comparison with single layer helical baffles.

Halle et al [7] conducted a study on shell side pressure drop by conducting experiments on 24 different segmental baffled bundle configurations of shell and tube heat exchanger. The heat exchangers are tested with water and overall progressive pressure drop across the various sections of the heat exchanger is measured. Gaddis and Gnielinski [8] also focused on using segmental baffles in a shell and tube heat exchanger to evaluate the pressure drop. The correlations developed are enough to see the effect of bypass streams and leakage for calculating of pressure drop. Another work reported by Eryener [9] studied the effect of spacing of baffles and baffle cut on the heat transfer and pressure drop. Through this work they found the optimum ratio for shell diameter and baffle spacing. The shell side heat transfer and flow resistance is observed to be higher in segmental baffle heat exchangers than in helical baffles in a study done by Wang et al [10]. Singh [11] conducted thermo hydraulic analysis on a shell and tube heat exchanger at different orientations with segmental type baffles. It is noticed that an increase in Reynolds number gave rise to pressure drop and the Nusselt number. The experiment is conducted with angular orientations of $0^{\circ}, 30^{\circ}$ and $60^{\circ}$ of the segmental baffles with laminar flow. The effect of various loading conditions is studied by Dubey et al [12] and it is concluded that the effectiveness is dependent on the turbulence provided and the insulation provided is well below the critical level of insulation. Sparrow [13] conducted experiments to see the effect of inter baffle spacing on pressure drop and heat transfer coefficient across the shell side of the heat exchanger. It is concluded that a reduction in per-compartmental pressure drop due to reduction in inter baffle spacing. Yang and Hwang [14] performed numerical simulations to examine the turbulent heat transfer enhancement by inserting a porous media in the pipe. The optimum porous radius ratio is obtained as 0.8 which can be employed for enhancing the heat transfer. Karno and Ajib [15] investigated the effect of transverse and longitudinal tube pitch on the pressure drop and heat transfer coefficient on a shell and tube heat exchanger. The two different types of tube arrangement considered during the study is staggered and in-line tube arrangement. Kistler and Chenoweth [16] studied the changes in shell side pressure drop by varying the baffle spacing, tube field pattern and nozzle size for a shell on a heat exchanger using segmental baffles. The predictions of the pressure drop are very close to the experimental values. Pekdemir et al [17] measured the pressure drop with E-type segmental baffles near the shell side of a cylindrical type shell and tube heat exchanger. Another work reported by Ajib and Karno [18] point out the influence of baffle number and baffle cut on the pressure drop and heat transfer coefficient with segmental baffles. The multidimensional, thermo-hydraulic numerical modeling of the shell and tube heat exchanger with porosity, surface permeability and distributed resistance is developed by Sha et al [19]. Raj and Ganne [20] analyzed the effects of baffle inclination angle on fluid flow in the shell side of a shell and tube type heat exchanger. The experiment consisted of three different baffle inclination angles of heat exchanger viz. $0^{\circ}, 10^{\circ}$ and $20^{\circ}$. The experiment showed that the shell side pressure drop decreased as the baffle inclination angle increased but the variation in shell side outlet temperature is very less. A $20^{\circ}$ baffle inclination showed the minimum increase in pressure drop (4\%) and better performance as compared to other models.

In the recent era, due to increased research and technological advancements in the area of nanotechnology, a lot of promising results have surfaced out and the use of nanofluids in place of normal fluids is one of the significant one. The use of nanofluids has a very high impact on the performance of a shell and tube heat exchanger mainly on its pressure drop and heat transfer. Nanofluid is a fluid in which the particles size is in nanometers and the particles form a colloidal suspension with the base fluid. The particles used in the nanofluids are mainly oxides, metals, etc. The use of nanoparticles in the heat exchanger has a significant role in the heat transfer enhancement and there are a number of parameters which affects the performance of the nanofluid based heat exchangers. The properties of nanofluids change with the nanoparticles used, size of the nanoparticles and its concentration along with the base fluid.

Albadr et al [21] conducted several experiments using different concentrations of $\mathrm{Al}_{2} \mathrm{O}_{3}$ nanofluid to see its effect on the heat transfer of a heat exchanger. It is perceived that the heat transfer coefficient is higher with nanofluids rather than $100 \%$ water. The study revealed that with an increase in the volume concentration and mass flow rate of the nanofluid the heat transfer coefficient is also found to be increased. Leong et al [22] conducted a few experiments on three different type of heat exchangers with segmental type, $25^{\circ}$ helical and $50^{\circ}$ helical baffles operated with varying concentrations of $\mathrm{CuO}$ nanoparticles immersed in ethylene glycol (base fluid). The experiment showed significant heat transfer coefficient with $25^{\circ}$ helical baffles but the pressure drop recorded is lowest in case of $50^{\circ}$ helical baffle heat exchanger. The heat transfer coefficient increased with addition of nanoparticles.

The CFD has been used as a very promising tool for numerical simulation in order to solve numerous heat transfer problems such as the ones in this study. It can give a better insight into the flow of the fluid inside the heat exchanger. For a successful CFD simulation to complete a lot of computing time and memory is required and thus the number of prototypes needed to be created for the study is reduced. The standard $\mathrm{k}-\varepsilon$ model is among the various turbulence models used to investigate the effect of various configurations on a particular fluid flow and heat transfer problem. It consists of two transport equations which solves the rate of turbulence dissipation ' $\varepsilon$ ' and the kinetic energy ' $\mathrm{k}$ '. The results obtained from the numerical analysis using ANSYS CFX tool agrees with the experimental results.

In the present work, a shell and tube type heat exchanger with 7 tubes and 6 segmental baffles is modeled for validation from the research paper mentioned in the literature [3]. The investigation on heat exchanger is divided into two phases. In the first phase the variation in geometric parameters on heat transfer enhancement is studied. The variation in geometric parameters considered in this paper includes increment in tube diameter, unequal baffle spacing and reduction in number of tubes. The second phase consists of study with nanofluid and its effect on pressure drop and heat transfer coefficient. In this phase different volume 
fractions of nanofluid $(0.5 \%, 0.75 \%, 1 \%, 1.25 \%$ and $1.5 \%)$ on pressure drop and heat transfer coefficient is studied.

\section{Motivation}

The geometric parameters are the main factors which affects the performance of any type of heat exchanger. The concept of unequal baffle spacing, increment in the tube diameter and reduction in the number of tubes along with constant triangular pitch has been discussed in few literatures only. Upon geometric optimization, the nature of shell and tube fluid on the shell and tube heat exchanger is analysed.

There are a few papers in which nanofluids are admitted across the shell side of a heat exchanger. In most of the studies, the nanofluids are passed through the tubes and a common observation is that the heat transfer characteristics improved greatly. While the heat transfer coefficient increased greatly, the increase in the pressure drop got neglected. There has to be an optimum condition in which both the parameters are compromised such that the ratio between heat transfer coefficient and pressure drop is maximum so as to increase the economics of energy used. The main driving force of the present study is to optimize the amount of energy used in the shell and tube heat exchanger.

\section{Numerical Simulation}

The numerical simulation is categorized into three parts viz. pre-processing, processing and post-processing. In the first part (pre-processing), the geometry of the shell and tube heat exchanger is modeled. The modifications are done in the original model [3] and three more models are created. The software used for modeling is SOLIDWORKS 2015. The parasolid file of the four models are created and imported in ANSYS ICEM CFD 15 for discretization. The required parts such as baffles, inner and outer tubes, baffle covers, inlet and outlet, shell inlet and outlet, shell inner and outer covers, shell inlet and outlet walls, tube side walls and solid-solid baffle and tube connections are created. The different bodies such as fluid and solid tubes ( 7 each for original model), solid baffles (6), shell fluid (1) and shell solid (1) are created. The surface mesh parameters are assigned to each of the parts appropriately and a tetrahedral mesh is generated. The generated mesh is imported in ANSYS CFX 15 and the different domains such as fluid tubes, solid tubes, solid baffles, shell solid, shell fluid and different interfaces such as fluid-solid baffles, fluid-solid inner tubes, fluid-solid outer tubes, fluid-solid shell inner cover, solid-solid baffle covers and solid-solid baffles and tubes connections are created. The boundary conditions are assigned to each of the domains and the model is then ready to be simulated.

In the second part (processing), a three dimensional fluid flow field through the shell and tube heat exchanger is obtained by solving the required equations in all three directions ( $\mathrm{x}, \mathrm{y}$ and $\mathrm{z}$ directions). The governing equations used are (i) mass conservation (ii) momentum conservation (iii) energy conservation and these are solved in ANSYS CFX 15. The default convergence criterion of 10-4 is taken for mass, momentum, energy and other residuals.
In the third part (post-processing), the numerical results obtained from the CFD analysis are post-processed and the charts, streamlines, contours of temperature, velocity and pressure drops in the shell side are obtained. The elaborative discussion of this is detailed below in the following sections.

\subsection{Geometric Modeling}

In the present study, a shell and tube type heat exchanger is modeled by means of SOLIDWORKS 2015 and the geometric parameters involved in the modeling are presented in Table 2. The original model is modified and three different configurations are created in the SOLIDWORKS software by varying the following parameters:-

(i) Tube diameter

(ii) Tube number

(iii) Baffle number and spacing for examining the changes in the CFD analysis results.

The original model with 6 segmental baffles and 7 tubes is shown in Fig. 1(a). The modified configuration with finite volume discretization is presented in Fig. 1(b). The working fluid for the three modified cases is with water on both the sides of the heat exchanger.

Next, the CFD analysis of the original model is carried out with water and nanofluid for five different volume fractions (i) $0.5 \%$ (ii) $0.75 \%$ (iii) $1.0 \%$ (iv) $1.25 \%$ (v) $1.5 \%$ with water through the tubes and nanofluid through the shell. The properties of the nanofluid namely thermal conductivity, viscosity, density, specific heat capacity and are calculated by the equations (6-11) and the same is presented in Table 1.

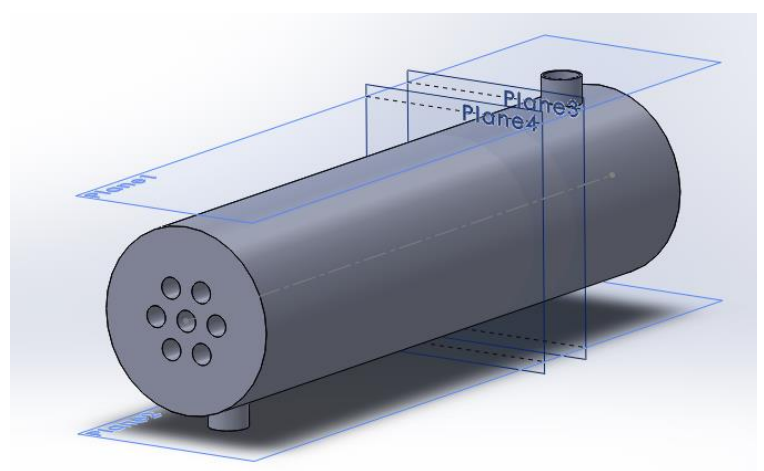

(a)

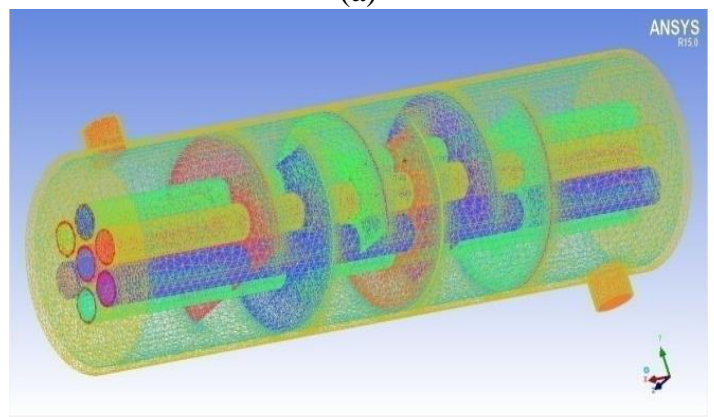

(b)

Figure 1. Geometric model of (a) shell and tube heat exchanger (b) Finite volume discretization of the model

Table 1. Properties of nanofluid.

\begin{tabular}{lllllllllll}
\hline$\varnothing$ & $\rho_{\mathrm{w}}$ & $\rho_{\mathrm{p}}$ & $\mathrm{C}_{\mathrm{pp}}$ & $\mathrm{C}_{\mathrm{pp}}$ & $\mathrm{k}_{\mathrm{w}}$ & $\mathrm{k}_{\mathrm{p}}$ & $\rho_{\mathrm{nf}}$ & $\mathrm{C}_{\mathrm{pnf}}$ & $\mu_{\mathrm{nf}}$ & $\mathrm{k}_{\mathrm{nf}}$ \\
\hline 0.005 & 1000 & 3970 & 4187 & 765 & 0.605 & 40 & 1014.85 & 4120.067 & 0.001043 & 1.014408 \\
0.0075 & 1000 & 3970 & 4187 & 765 & 0.605 & 40 & 1022.275 & 4087.33 & 0.001065 & 1.021664 \\
0.01 & 1000 & 3970 & 4187 & 765 & 0.605 & 40 & 1029.7 & 4055.065 & 0.001089 & 1.028956 \\
0.0125 & 1000 & 3970 & 4187 & 765 & 0.605 & 40 & 1037.125 & 4023.262 & 0.001114 & 1.036282 \\
0.015 & 1000 & 3970 & 4187 & 765 & 0.605 & 40 & 1044.55 & 3991.911 & 0.001141 & 1.043644 \\
\hline
\end{tabular}


Table 2. Design and geometric parameters of the heat exchanger.

\begin{tabular}{|c|c|c|c|}
\hline Parameters & Notation & Unit & Value \\
\hline Length of heat exchanger & $\mathrm{L}$ & $\mathrm{mm}$ & 1000 \\
\hline Shell inside diameter & $\mathrm{D}_{\mathrm{i}}$ & $\mathrm{mm}$ & 254 \\
\hline Shell outside diameter & $\mathrm{D}_{\mathrm{o}}$ & $\mathrm{mm}$ & 270 \\
\hline Number of tubes & $\mathrm{N}_{\mathrm{T}}$ & - & 7 \\
\hline Tube outer diameter & $\mathrm{d}_{\mathrm{o}}$ & $\mathrm{mm}$ & 38.1 \\
\hline Tube inner diameter & $\mathrm{d}_{\mathrm{i}}$ & $\mathrm{mm}$ & 31.3 \\
\hline Tube pitch(triangular) & $\mathrm{p}$ & $\mathrm{mm}$ & 50.8 \\
\hline Shell side inlet tube inner diameter & $\mathrm{d}_{\text {o(iss) }}$ & $\mathrm{mm}$ & 57 \\
\hline Shell side inlet tube outer diameter & $\mathrm{d}_{\mathrm{i}(\mathrm{iss})}$ & $\mathrm{mm}$ & 50 \\
\hline $\begin{array}{l}\text { Shell side outlet tube inner } \\
\text { diameter }\end{array}$ & $\mathrm{d}_{\mathrm{o}(\mathrm{oss})}$ & $\mathrm{mm}$ & 57 \\
\hline $\begin{array}{l}\text { Shell side outlet tube outer } \\
\text { diameter }\end{array}$ & $\mathrm{d}_{\mathrm{i}(\mathrm{oss})}$ & $\mathrm{mm}$ & 50 \\
\hline Baffle number & $\mathrm{N}_{\mathrm{b}}$ & - & 6 \\
\hline Pitch of the baffle & B & $\mathrm{mm}$ & 100 \\
\hline Thickness of the baffle & $\mathrm{B}_{\mathrm{t}}$ & $\mathrm{mm}$ & 4 \\
\hline Helix angle & $\beta$ & $\left({ }^{\circ}\right)$ & 0 \\
\hline Baffle cut & $\mathrm{B}_{\mathrm{c}}$ & $\%$ & 25 \\
\hline
\end{tabular}

\subsection{Governing Equations}

The governing equations used to solve the mass, momentum and energy in the computational domain are specified by the Eqs. (1-3) respectively. The turbulence developed along the fluid domain is obtained by Standard $k$ $\varepsilon$ mode of closure as specified in the below Eqs. (4) and (5) for predicting the turbulent kinetic energy and turbulent dissipation rate respectively.

Continuity equation:

$\frac{\partial(\rho u)}{\partial x}+\frac{\partial(\rho v)}{\partial y}+\frac{\partial(\rho w)}{\partial z}=0$

Momentum equation:

$\mathrm{u}_{\mathrm{j}} \frac{\partial \mathrm{u}_{\mathrm{i}}}{\partial \mathrm{x}_{\mathrm{j}}}=-\frac{1}{\rho} \frac{\partial \mathrm{P}}{\partial \mathrm{x}_{\mathrm{i}}}+v \frac{\partial^{2} \mathrm{u}}{\partial \mathrm{x}_{\mathrm{j}} \partial \mathrm{x}_{\mathrm{j}}}$

Energy equation:

$\mathrm{u}_{\mathrm{j}} \frac{\partial \mathrm{T}}{\partial \mathrm{x}_{\mathrm{j}}}=\frac{\mathrm{k}}{\rho \mathrm{C}_{\mathrm{p}}} \frac{\partial^{2} \mathrm{~T}}{\partial \mathrm{x}_{\mathrm{j}} \partial \mathrm{x}_{\mathrm{j}}}$

Turbulent kinetic energy equation:

$\frac{\partial \mathrm{k}}{\partial \mathrm{t}}+\overline{\mathrm{u}_{\mathrm{j}}} \frac{\partial \mathrm{k}}{\partial \mathrm{x}_{\mathrm{j}}}=v_{\mathrm{T}}\left[\left(\frac{\partial \overline{\mathrm{u}_{1}}}{\partial \mathrm{x}_{\mathrm{j}}}+\frac{\partial \overline{\mathrm{u}_{\mathrm{j}}}}{\partial \mathrm{x}_{\mathrm{i}}}\right) \frac{\partial \overline{\mathrm{u}_{1}}}{\partial \mathrm{x}_{\mathrm{j}}}\right]-\varepsilon+\frac{\partial}{\partial \mathrm{x}_{\mathrm{j}}}\left[\left(v+\frac{v_{\mathrm{T}}}{\sigma_{\mathrm{k}}}\right) \frac{\partial \mathrm{k}}{\partial \mathrm{x}_{\mathrm{j}}}\right]$

Turbulent kinetic energy dissipation rate:

$$
\begin{gathered}
\frac{\partial \varepsilon}{\partial \mathrm{t}}+\overline{\mathrm{u}}_{\mathrm{j}} \frac{\partial \varepsilon}{\partial \mathrm{x}_{\mathrm{j}}}=\mathrm{C}_{\varepsilon 1} \nu_{\mathrm{T}} \frac{\varepsilon}{\mathrm{k}}\left[\left(\frac{\partial \overline{\mathrm{u}_{1}}}{\partial \mathrm{x}_{\mathrm{j}}}+\frac{\partial \overline{\mathrm{u}_{\mathrm{j}}}}{\partial \mathrm{x}_{\mathrm{i}}}\right) \frac{\partial \overline{\mathrm{u}_{1}}}{\partial \mathrm{x}_{\mathrm{j}}}\right]+\mathrm{C}_{\varepsilon 2} \frac{\varepsilon^{2}}{\mathrm{k}}+ \\
\frac{\partial}{\partial \mathrm{x}_{\mathrm{j}}}\left[\left(\nu+\frac{\nu_{\mathrm{T}}}{\sigma_{\varepsilon}}\right) \frac{\partial \varepsilon}{\partial \mathrm{x}_{\mathrm{j}}}\right]
\end{gathered}
$$

\subsection{Boundary Conditions}

The values of temperature and mass flow rate are given as boundary condition for the inlet nozzle near shell and tube inlets of the shell and tube heat exchanger. The subsonic flow regime is selected with a turbulence of medium intensity $(5 \%)$. The mass and momentum values are calculated over average static pressure and a gauge pressure of zero is assigned to the outlet nozzle and tube outlets. This is done in order to attain the relative pressure drop across the inlet and outlet of tubes and shell. No slip condition is given to all surfaces. The shell outer cover and tube side covers are assigned as boundary with zero heat flux the shell being assumed as perfectly insulated. The tubes and baffles are considered to be manufactured from stainless steel. The complete description of the boundary conditions is presented in Table 3. The flow is steady and incompressible.

The various properties of the nanofluid such as specific heat capacity, density, thermal conductivity dynamic viscosity are calculated by a set of Eqs. (6-11).

Various domains have been created in the model which indicates the volume which is composed of either solid or fluid. The inner portion of the tubes and the shell are considered as fluid domains because these are the regions through which the fluid flows. Next, the regions included in the baffles and the thickness of the tube and shell are considered solid as they are made up of stainless steel. Now, since many domains have been created, a number of interfaces will also be needed to be made like:

The fluid-solid interface between the fluid tube and solid tube, solid tube and shell fluid, solid baffles and shell fluid and shell solid and shell fluid domains.

The solid-solid interface between the solid baffles and solid tube, solid baffles and the shell solid and a part of solid tubes and the shell solid domains.

The domains and interfaces are depicted in Table 4.

$$
\begin{aligned}
& \varnothing=\frac{\text { Volume of nanoparticle }}{\text { (Volume of nanoparticle+Volume of water) }} \times 100 \\
& \varnothing=\frac{\frac{\mathrm{w}_{\text {nanoparticle }}}{\rho_{\text {nanoparticle }}}}{\left(\frac{\mathrm{W}_{\text {nanoparticle }}}{\rho_{\text {nanoparticle }}}+\frac{\mathrm{W}_{\text {water }}}{\rho_{\text {water }}}\right)} \times 100 \\
& \rho_{\text {nanofluid }}=\left\{\varnothing X \rho_{\text {nanoparticle }}\right\}+\left\{(1-\emptyset) X \rho_{\text {water }}\right\} \\
& \mathrm{C}_{\mathrm{p} \text {,nanofluid }}= \\
& \underline{\left[\emptyset \times\left\{\rho_{\text {nanoparticle }} X C_{p, \text { nanoparticle }}\right\}\right]+\left[(1-\emptyset) X\left\{\rho_{\text {water }} \times C_{p, \text { water }}\right\}\right]} \\
& \rho_{\text {nanofluid }} \\
& \mu_{\text {nanofluid }}=\left\{1+(7.3 \times \varnothing)+\left(123 \times \emptyset^{2}\right)\right\} \mu_{\text {water }} \\
& \mathrm{k}_{\text {nanofluid }}= \\
& \mathrm{k}_{\text {nanoparticle }}+\left(2 \mathrm{X} \mathrm{k}_{\mathrm{water}}\right)+\left\{2 \mathrm{X}\left(\mathrm{k}_{\text {nanoparticle }}-\mathrm{k}_{\mathrm{water}}\right) \mathrm{X} \emptyset\right\} \\
& \mathrm{k}_{\text {nanoparticle }}+\left(2 \mathrm{X} \mathrm{k}_{\text {water }}\right)-\left\{\left(\mathrm{k}_{\text {nanoparticle }}-\mathrm{k}_{\mathrm{water}}\right) \mathrm{X} \emptyset\right\}
\end{aligned}
$$

Table 3. Boundary conditions for validation.

\begin{tabular}{|l|l|l|}
\hline Parameters & Shell side & Tube side \\
\hline Inlet temperature & $353 \mathrm{~K}$ & $300 \mathrm{~K}$ \\
\hline Mass flow rate & $1 \mathrm{~kg} / \mathrm{sec} \quad$ & $3.5 \mathrm{~kg} / \mathrm{sec}$ \\
\hline Outlet & $\begin{array}{l}\text { Zero gauge } \\
\text { pressure }\end{array}$ & $\begin{array}{l}\text { Zero gauge } \\
\text { pressure }\end{array}$ \\
\hline Fluid & Hot water & Cold water \\
\hline $\begin{array}{l}\text { Material (Solid } \\
\text { shell and tube } \\
\text { domains) }\end{array}$ & Stainless steel & Stainless steel \\
\hline $\begin{array}{l}\text { Cover (Shell } \\
\text { wall boundary) }\end{array}$ & $\begin{array}{l}\text { Zero heat flux } \\
\text { (adiabatic) }\end{array}$ & - \\
\hline
\end{tabular}

Assumptions:

- The fluid flow is steady and incompressible.

- No slip boundary condition is provided at the walls.

- Outlet boundary conditions of 0 Pascal gauge pressure is specified for both shell and tube outlets.

- The variation of properties like thermal conductivity, density and viscosity with respect to temperature are considered to be negligible. 


\subsection{Mesh Generation and Grid Independence Study}

The tetrahedral mesh for the present shell and tube heat exchanger configuration is generated using ANSYS ICEM CFD 15.0 tool. The shell and tube heat exchanger for the specification provided in Table. 2 is discretized using finite volume approximation. The original configuration have been discretized with 15, 00,000 elements, 20, 00,000 and 49, 00,000 tetrahedral elements. It has been found that the predicted numerical results with $20,00,000$ and $49,00,000$ elements do not vary much and hence it is found that the numerical results are grid independent beyond 20,00,000 elements for the original shell and tube heat exchanger considered. The tetrahedral meshing of the original model is depicted in Fig. 2. Similar grid independence study has been carried out for all the models considered in this study. The grid independent tetrahedral elements for the model with 6 number of tubes is 19,00,000 and for the model with increased diameter of the tubes is $21,50,000$ and it is around $19,50,000$ elements for the model with unequal baffle spacing with reduced number of baffles.

\subsection{Turbulence Model}

In the present study, the flow through the shell and tube type heat exchanger is turbulent so the appropriate turbulence model is selected for solving the necessary governing equations. The $\mathrm{k}-\mathcal{E}$ turbulence model is selected for the analysis as its usage fits appropriately in the current problem.

Table 4. Domains and interfaces.

\begin{tabular}{|c|c|c|c|}
\hline $\begin{array}{l}\text { Domain } \\
\text { location }\end{array}$ & Domain & Domain interface & Interfac \\
\hline fluid_tube_1 & fluid & flso_innertube_1 & flso \\
\hline fluid_tube_2 & fluid & flso_innertube_2 & flso \\
\hline fluid_tube_3 & fluid & flso_innertube_3 & flso \\
\hline fluid_tube_4 & fluid & flso_innertube_4 & flso \\
\hline fluid_tube_5 & fluid & flso_innertube_5 & flso \\
\hline fluid_tube_6 & fluid & flso_innertube_6 & flso \\
\hline fluid_tube_7 & fluid & flso_innertube_7 & flso \\
\hline solid_tube_1 & solid & $\begin{array}{l}\text { flso_innertube_1 } \\
\text { flso_outertube_1 } \\
\text { soso_b(1-7)_t1 }\end{array}$ & $\begin{array}{l}\text { flso } \\
\text { flso } \\
\text { soso }\end{array}$ \\
\hline solid_tube_2 & solid & $\begin{array}{l}\text { flso_innertube_2 } \\
\text { flso_outertube_2 } \\
\text { soso_b(1-7)_t2 }\end{array}$ & $\begin{array}{l}\text { flso } \\
\text { flso } \\
\text { soso }\end{array}$ \\
\hline solid_tube_3 & solid & $\begin{array}{l}\text { flso_innertube_3 } \\
\text { flso_outertube_3 } \\
\text { soso_b(1-7)_t3 }\end{array}$ & $\begin{array}{l}\text { flso } \\
\text { flso } \\
\text { soso }\end{array}$ \\
\hline solid_tube_4 & solid & $\begin{array}{l}\text { flso_innertube_4 } \\
\text { flso_outertube_4 } \\
\text { soso_b(1-7)_t4 }\end{array}$ & $\begin{array}{l}\text { flso } \\
\text { flso } \\
\text { soso } \\
\end{array}$ \\
\hline solid_tube_5 & solid & $\begin{array}{l}\text { flso_innertube_5 } \\
\text { flso_outertube_5 } \\
\text { soso_b(1-7)_t5 }\end{array}$ & \begin{tabular}{|l|} 
flso \\
flso \\
soso
\end{tabular} \\
\hline solid_tube_6 & solid & $\begin{array}{l}\text { flso_innertube_6 } \\
\text { flso_outertube_6 } \\
\text { soso_b(1-7)_t6 }\end{array}$ & $\begin{array}{l}\text { flso } \\
\text { flso } \\
\text { soso } \\
\end{array}$ \\
\hline solid_tube_7 & solid & $\begin{array}{l}\text { flso_innertube_7 } \\
\text { flso_outertube_7 } \\
\text { soso_b(1-7)_t7 }\end{array}$ & $\begin{array}{l}\text { flso } \\
\text { flso } \\
\text { soso }\end{array}$ \\
\hline solid_baffle_1 & solid & $\begin{array}{l}\text { flso_baffle_1 } \\
\text { soso_b1_t }(1-7) \\
\text { soso_bafflecover_1 }\end{array}$ & $\begin{array}{l}\text { flso } \\
\text { soso } \\
\text { soso }\end{array}$ \\
\hline solid_baffle_2 & solid & $\begin{array}{l}\text { flso_baffle_2 } \\
\text { soso_b2_t }(1-7) \\
\text { soso_bafflecover_2 }\end{array}$ & $\begin{array}{l}\text { flso } \\
\text { soso } \\
\text { soso }\end{array}$ \\
\hline solid_baffle_3 & solid & $\begin{array}{l}\text { flso_baffle_3 } \\
\text { soso_b3_t }(1-7) \\
\text { soso_bafflecover_3 }\end{array}$ & $\begin{array}{l}\text { flso } \\
\text { soso } \\
\text { soso }\end{array}$ \\
\hline solid_baffle_4 & solid & $\begin{array}{l}\text { flso_baffle_4 } \\
\text { soso_b4_t }(1-7) \\
\text { soso_bafflecover_4 }\end{array}$ & $\begin{array}{l}\text { flso } \\
\text { soso } \\
\text { soso }\end{array}$ \\
\hline solid_baffle_5 & solid & flso_baffle_5 & flso \\
\hline
\end{tabular}

\begin{tabular}{|c|c|c|c|}
\hline & & $\begin{array}{l}\text { Soso_b5_t(1-7) } \\
\text { soso_bafflecover_5 }\end{array}$ & $\begin{array}{l}\text { soso } \\
\text { soso }\end{array}$ \\
\hline solid_baffle_6 & solid & $\begin{array}{l}\text { flso_baffle_6 } \\
\text { soso_b6_t }(1-7) \\
\text { soso_bafflecover_6 }\end{array}$ & $\begin{array}{l}\text { flso } \\
\text { soso } \\
\text { soso }\end{array}$ \\
\hline shell_fluid & fluid & $\begin{array}{l}\text { flso_outertube_1 } \\
\text { flso_outertube_2 } \\
\text { flso_outertube_3 } \\
\text { flso_outertube_4 } \\
\text { flso_outertube_5 } \\
\text { flso_outertube_6 } \\
\text { flso_outertube_7 } \\
\text { flso_baffle_1 } \\
\text { flso_baffle_2 } \\
\text { flso_baffle_3 } \\
\text { flso_baffle_4 } \\
\text { flso_baffle_5 } \\
\text { flso_baffle_6 } \\
\text { flso_shell_inner_cover }\end{array}$ & $\begin{array}{l}\text { flso } \\
\text { flso } \\
\text { flso } \\
\text { flso } \\
\text { flso } \\
\text { flso } \\
\text { flso } \\
\text { flso } \\
\text { flso } \\
\text { flso } \\
\text { flso } \\
\text { flso } \\
\text { flso } \\
\text { flso }\end{array}$ \\
\hline shell_solid & solid & $\begin{array}{l}\text { soso_bafflecover_1 } \\
\text { soso_bafflecover_2 } \\
\text { soso_bafflecover_3 } \\
\text { soso_bafflecover_4 } \\
\text { soso_bafflecover_5 } \\
\text { soso_bafflecover_6 } \\
\text { flso_shell_inner_cover }\end{array}$ & $\begin{array}{l}\text { soso } \\
\text { soso } \\
\text { soso } \\
\text { soso } \\
\text { soso } \\
\text { soso } \\
\text { flso }\end{array}$ \\
\hline
\end{tabular}

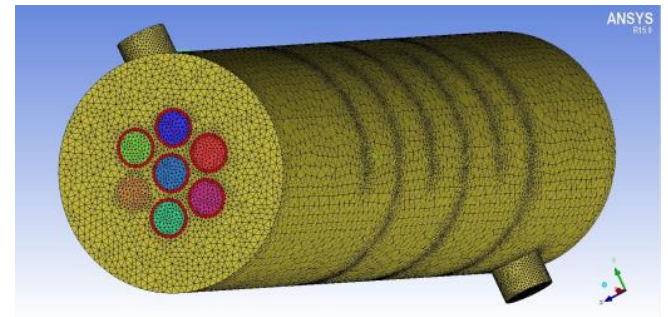

Figure 2. Tetrahedral meshing of shell and tube heat exchanger.

\section{Model Validations}

The results obtained from the simulation are validated with the data available for the same geometrical model used in the paper by Rad et al [3]. The velocity profile in one of the tubes is validated and is shown in Fig. 3.The velocity and temperature profiles under baffle 3 are validated and the same is shown in Fig. 4 and Fig. 5 respectively. The experimental values by Rad et al [3] are considered for the validation. It is found that the deviation between the experimental and simulated results is less than $5 \%$. As the values of these errors are within the permissible limit so, the numerical analysis can be further extended to other cases. The average Nusselt number in the tube side is calculated and matched with the Nusselt number computed using the Dittus and Boelter [24] equation for turbulent flow in tubes and the same is presented in Table 5. The equation is stated in Eq. 12.

$N u=0.023 R e^{0.8} \stackrel{0.4}{\operatorname{Pr}}\left(\frac{\mu_{b}}{\mu_{\text {wall }}}\right)^{0.14}$

Table 5: Result verification for simulated model.

\begin{tabular}{|l|l|l|l|}
\hline & Simulation & $\begin{array}{l}\text { Original } \\
\text { (theoretical) }\end{array}$ & $\begin{array}{l}\text { Relative } \\
\text { error (\%) }\end{array}$ \\
\hline $\begin{array}{l}\text { Tube-side } \\
\begin{array}{l}\text { Nusselt } \\
\text { number }\end{array}\end{array}$ & 150.028 & 156.02 & 3.846 \\
\hline
\end{tabular}




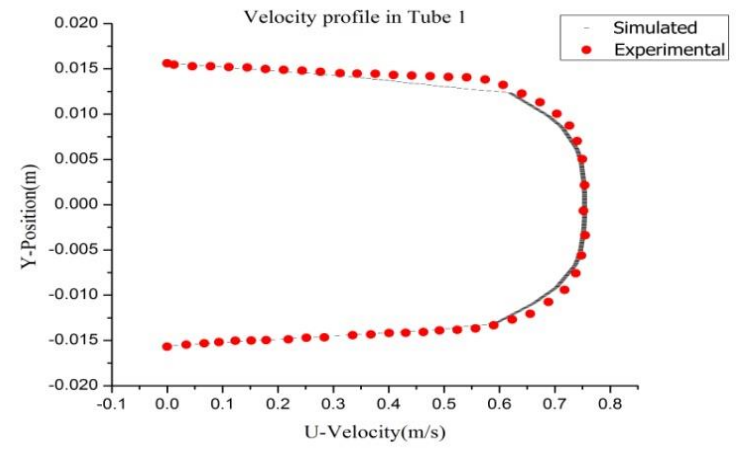

Figure 3. Velocity profile in tube 1.

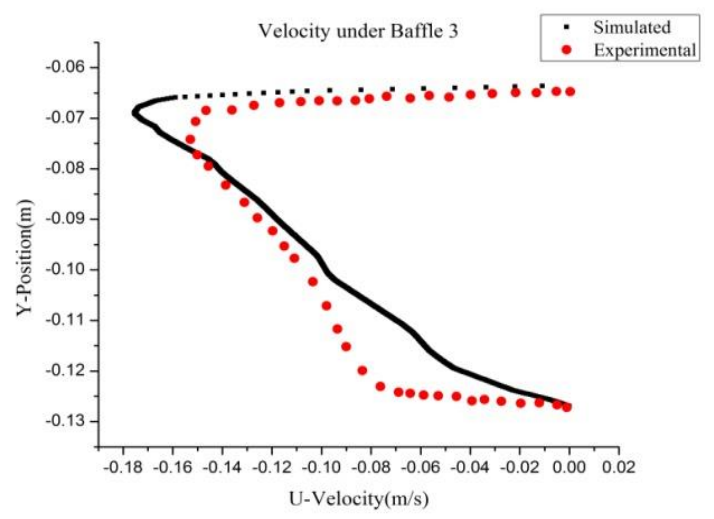

Figure 4. Velocity profile under baffle 3.

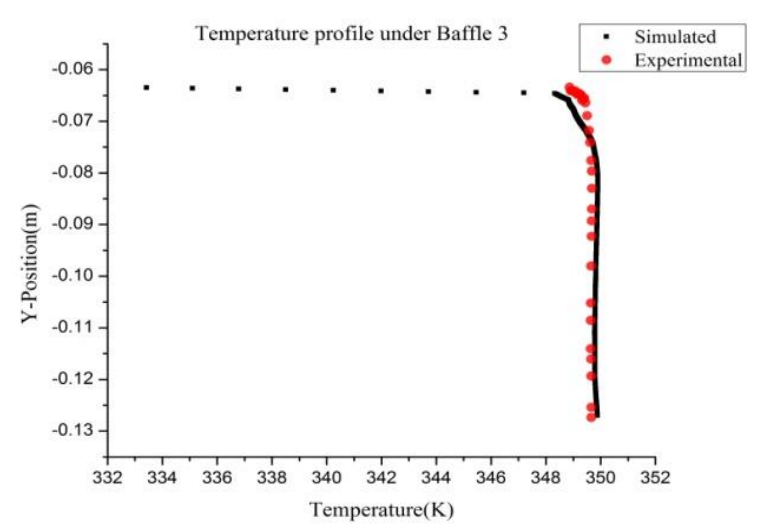

Figure 5. Temperature profile under baffle 3.

\section{Results and Discussions}

In this study the baffle spacing is changed and the effect of unequal baffle spacing is studied. The tube inner diameter is increased to $38.1 \mathrm{~mm}$ and its effect on heat transfer coefficient and pressure drop is analyzed. The number of tubes are reduced to 6 and the triangular pitch is maintained. The fluid on the shell side is changed to nanofluid and the CFD analysis is carried out with different volume fractions of nanofluid such as $0.5 \%$, $0.75 \%, 1 \%, 1.25 \%$ and $1.5 \%$ and its effect on heat transfer and pressure drop is studied. Hence a total of 8 cases apart from model required for validation are studied and discussed in this paper. The temperature and pressure contour in the original model having 7 tubes and 6 segmental baffles are presented in Fig. 6 and Fig. 7 respectively.

The ratio between the heat transfer coefficient and the pressure drop is tabulated in table 6 . The overall results are shown in table 6.

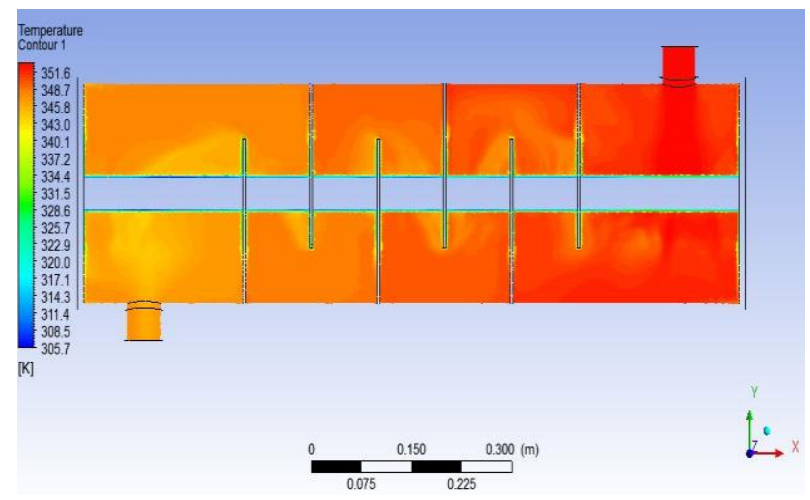

Figure 6. Temperature contour in original model.

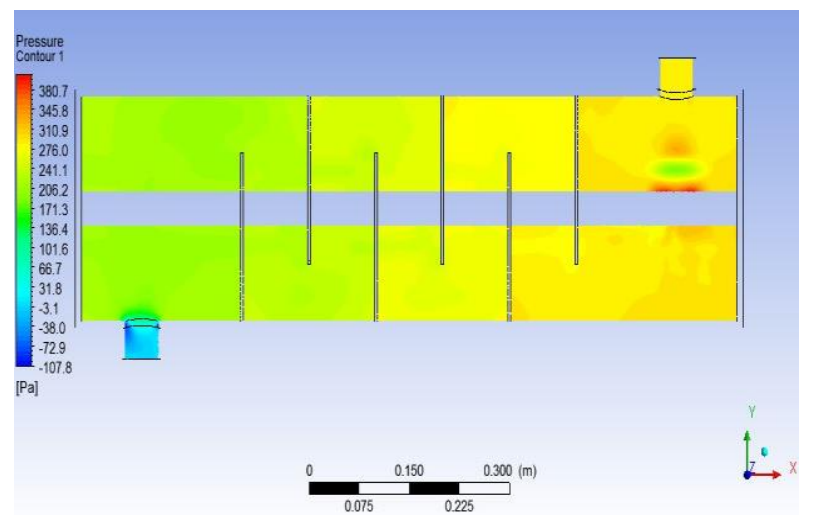

Figure 7. Pressure contour in original model.

\subsection{Effect of Nanofluid with Different Volume Fractions}

The CFD analysis is carried out with nanofluid of different volume fractions on the shell side and all the data necessary for the analysis are calculated through theoretical equations mentioned before in the paper (6-11). The values of the pressure drop and heat transfer coefficient for the different cases simulated are compared with the original model and are presented in Fig. 8(a) and (b) respectively.

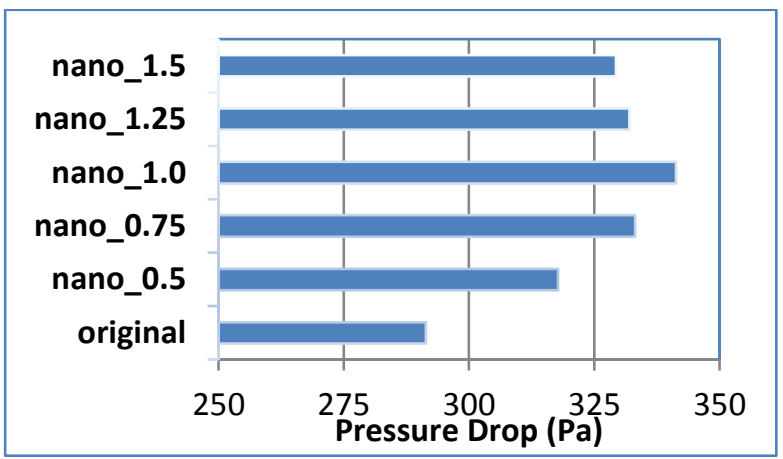

Figure 8. (a) Pressure drop.

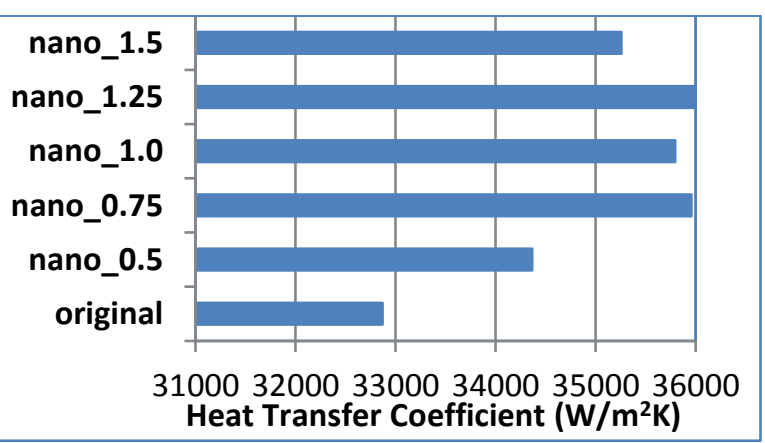

Figure 8. (b) Heat transfer coefficients for various concentrations of nanofluid. 
The pressure drop for all the nanofluids are relatively higher compared to the base working fluid as seen in Fig. 8(a). It is a general trend that the pressure drop should increases with increase in nanoparticle concentration.

But in the current study, the influence of nano particle viscosity has a major role up to its concentration of $1.0 \%$ and beyond that the reverse trends results and this may be due to the geometrical nature of the shell and tube heat exchanger which may have higher control over pressure drop rather than the nanoparticle concentration.

Because of the geometry of the shell and tube heat exchanger the nano-particles with $1.0 \%$ concentration may lead to more agglomeration compared to nano-particles with 1.25 and $1.5 \%$ concentrations. Thus the agglomeration of nanoparticles with respect to geometry may be influencing this variation in pressure drop.

The heat transfer coefficient generally increases with increase in concentration of nanoparticle concentration in the base fluid. This is because the thermal conductivity of the nano fluid is higher compared to base working fluid. But at higher concentration of nano particles, above 1.25 even though the nanoparticle thermal conductivity is higher in the base fluid, still the overall heat transfer coefficient decreases. This decrease may be due to the agglomeration of the nanoparticles with increased concentration. Although the thermal conductivity increases, a major part of the heat transfer takes place because of the chaotic movement of the nano particle decreases. Thus, the heat transfers co-efficient decreases after reaching a particular value of concentration.

\subsection{Effect of Unequal Baffle Spacing}

The original case is modeled with equal baffle spacing. In one of the modified model two baffles are removed from the middle which makes the case of unequal baffle spacing with a total of 4 baffles. Thus, it is understood that the heat exchanger performance is improved in the case of unequal baffle spacing with a reduction in the number of baffles. The pressure drop decreased because less turbulence is created due to less number of baffles and the heat transfer coefficient increased because the fluid remained in contact for a longer length of the tubes. The effect of the pressure drop and heat transfer coefficient is validated with the original model and the same is presented in Fig. 9(a) and (b) respectively.

\subsection{Effect of Tube Diameter}

The initial tube inner diameter is $31.3 \mathrm{~mm}$ which is later increased to $38.1 \mathrm{~mm}$. In one of the models the tube inner diameter is only increased and the other parameters are kept constant. In this case, although there is a slight reduction in the pressure drop, a significant decrease in the heat transfer coefficient is observed. Since the area of contact of the shell fluid with the tubes increased, the velocity decreased and correspondingly, the Reynolds number decreased. This caused a reduction in the Nusselt number and thus, the heat transfer coefficient decreased. The corresponding change in the pressure drop and heat transfer coefficient and pressure is shown in Fig. 9(a) and (b) respectively.

\subsection{Effect of Number of Tubes}

Initially the number of tubes are 7 in the original case. In this case the number of tubes is reduced to 6 in such a way that the triangular pitch is maintained. It can be understood that if the number of tubes is decreased, the velocity will increase for a given flow rate and thus, the Reynolds number increased. It led to an increase in the heat transfer coefficient at the expense of an increase in pressure drop. The variation of the same is presented in Fig. 9(a) and (b) respectively. The ratio of heat transfer coefficient to pressure drop for various geometrical models is depicted as shown in Fig. 10. The velocity streamlines are depicted in Fig. 11 for all the cases.

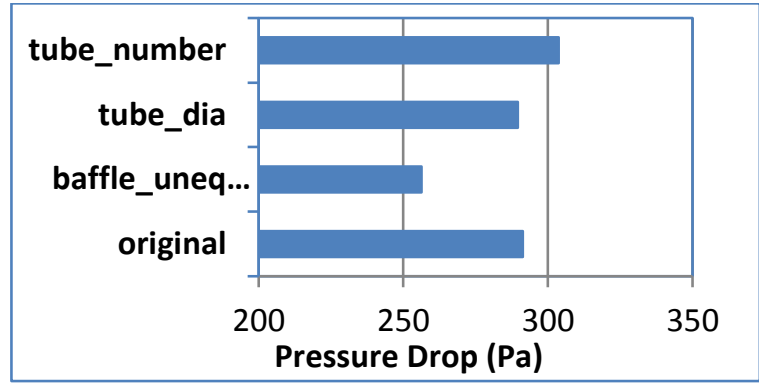

Figure 9. (a) Pressure drop.

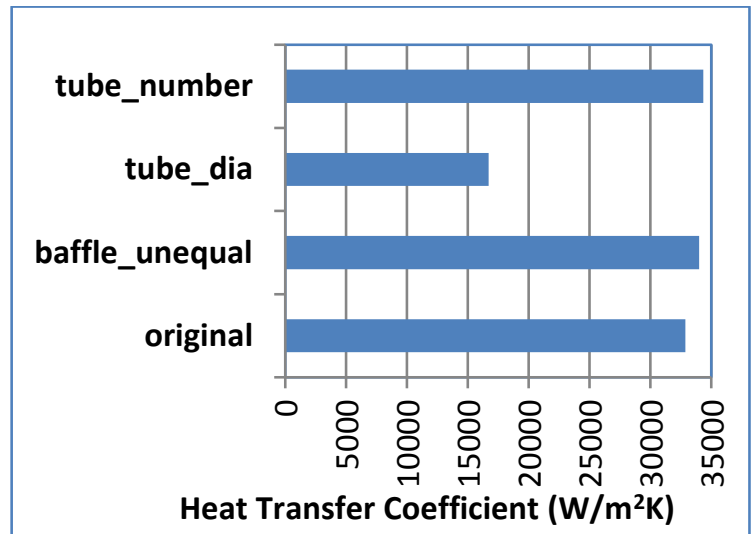

Figure 9. (b) Heat transfer coefficients for various geometric models.

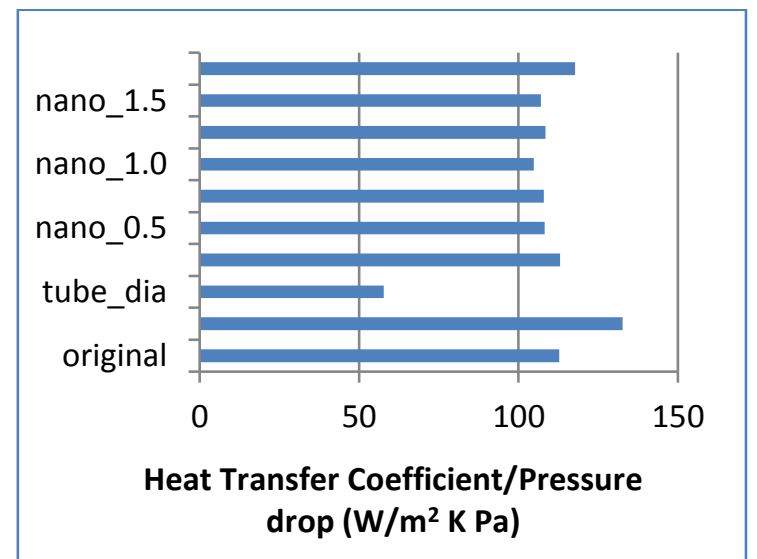

Figure 10. Comparison of heat exchanger with different conditions.

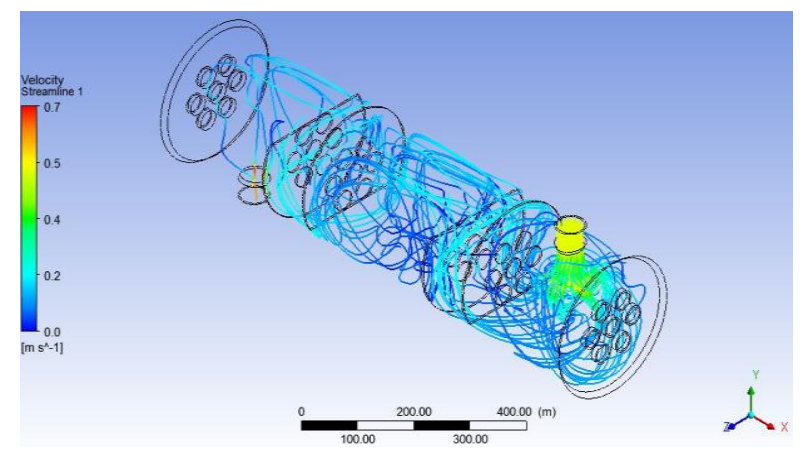

(a) 


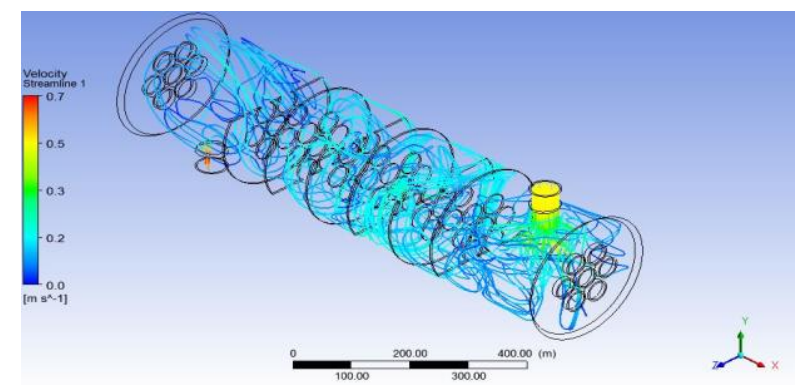

(b)

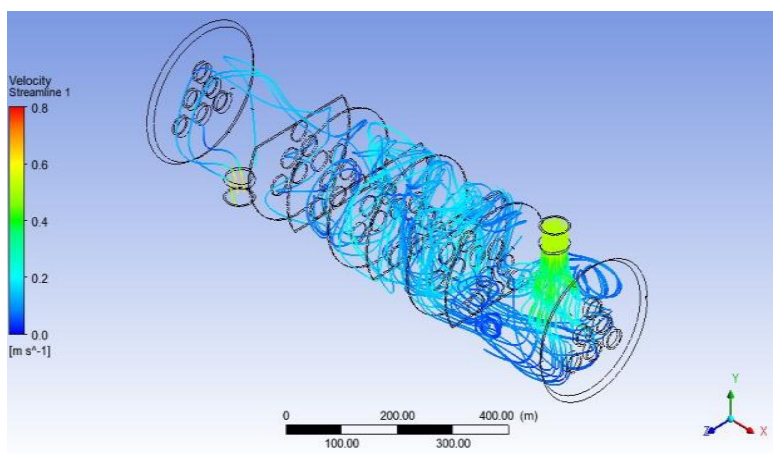

(c)

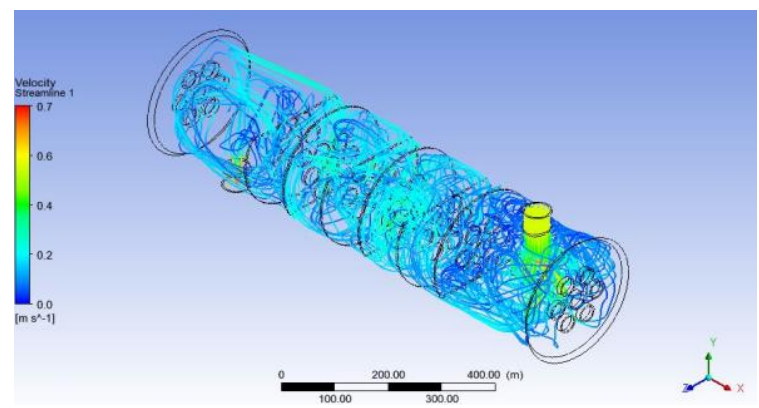

(d)

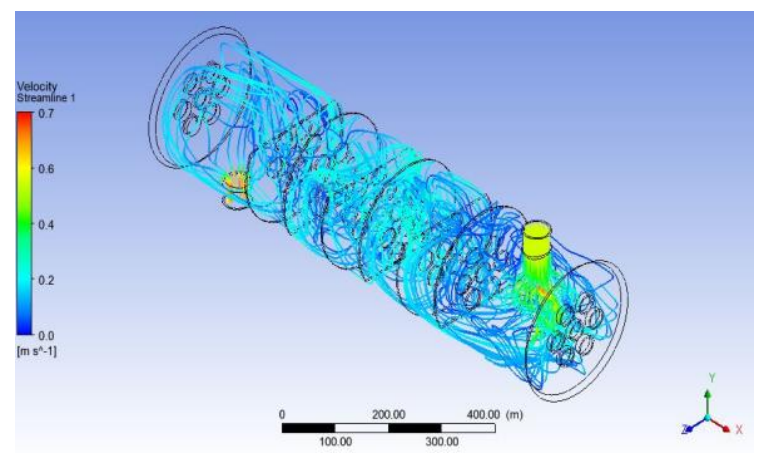

(e)

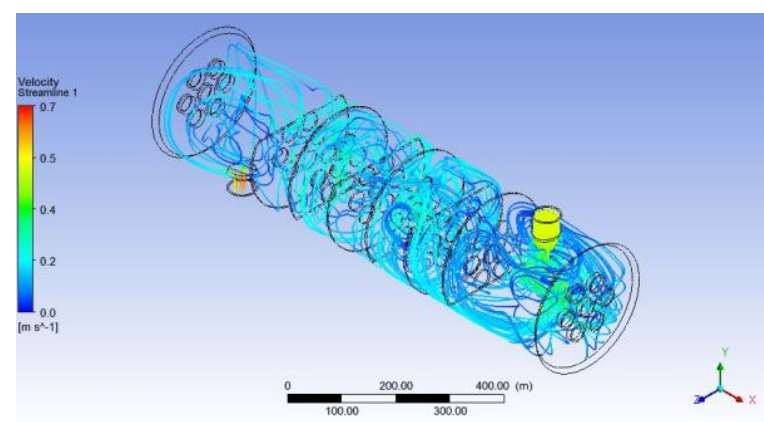

(f)

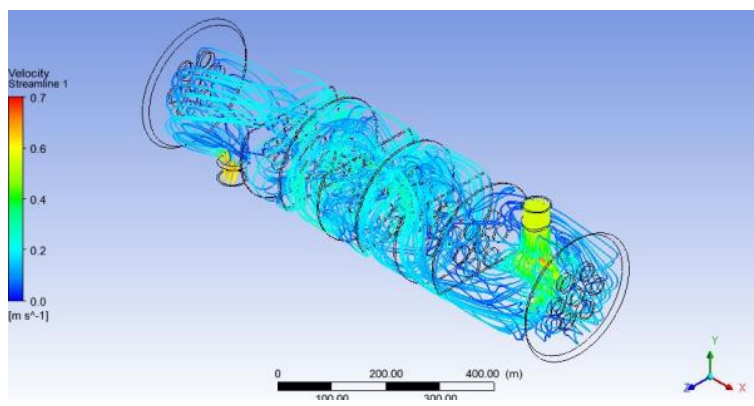

(g)

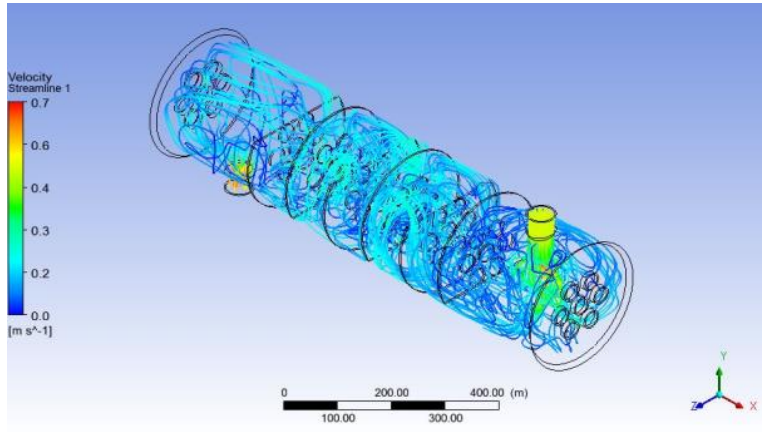

(h)

Figure 11. 3-D velocity streamlines for (a) unequal baffle spacing (b) tube diameter (c) tube number (d) $0.5 \%$ (e) $0.75 \% \quad(f) 1.0 \% \quad(g) 1.25 \%$ (h) $1.5 \%$ nanofluid volume concentration.

Table 6: Heat transfer coefficient, pressure drop and heat transfer coefficient/pressure drop for various models.

\begin{tabular}{|l|l|l|l|}
\hline Models & $\begin{array}{l}\text { Heat } \\
\text { transfer } \\
\text { coefficient } \\
\left.\text { (W/m } / \mathrm{m}^{2}\right)\end{array}$ & $\begin{array}{l}\text { Pressur } \\
\text { e drop } \\
\text { (Pa) }\end{array}$ & $\begin{array}{l}\text { Heat } \\
\text { transfer } \\
\text { coefficient/ } \\
\text { Pressure } \\
\text { drop (W/m } \\
\text { K Pa) }\end{array}$ \\
\hline \multicolumn{3}{|c|}{ Case A: Study with nanofluids } \\
\hline $\begin{array}{l}\text { Concentration of } \\
0.5 \%\end{array}$ & 34367.5 & 317.75 & 108.1571 \\
\hline $\begin{array}{l}\text { Concentration of } \\
0.75 \%\end{array}$ & 35959.19 & 333.17 & 107.9295 \\
\hline $\begin{array}{l}\text { Concentration of } \\
1.0 \%\end{array}$ & 35797.16 & 341.34 & 104.8696 \\
\hline $\begin{array}{l}\text { Concentration of } \\
1.25 \%\end{array}$ & 36000.07 & 332.01 & 108.43 \\
\hline $\begin{array}{l}\text { Concentration of } \\
1.5 \%\end{array}$ & 35256.38 & 329.32 & 107.0562 \\
\hline $\begin{array}{l}\text { Concentration of } \\
0.5 \%\end{array}$ & 36050.38 & 306.28 & 117.7017 \\
\hline \multicolumn{3}{|c|}{ Case B: Study with geometric parameters } \\
\hline $\begin{array}{l}\text { Unequal baffle } \\
\text { spacing and } \\
\text { reduction in } \\
\text { number of baffles }\end{array}$ & 34011.91 & 256.45 & 132.7219 \\
\hline $\begin{array}{l}\text { Increment in } \\
\text { diameter of tubes }\end{array}$ & 16715.21 & 289.55 & 157.72661 \\
\hline $\begin{array}{l}\text { Reduction in } \\
\text { number of tubes }\end{array}$ & 34338.6 & 303.71 & 113.0637 \\
\hline \multicolumn{3}{|c|}{} \\
\hline
\end{tabular}

\section{Results and discussions}

Case A: Study with nanofluids

- Concentration of $0.5 \%$

The heat transfer coefficient increased from 32868.02 $\mathrm{W} / \mathrm{m}^{2} \mathrm{~K}$ to $34367.5 \mathrm{~W} / \mathrm{m}^{2} \mathrm{~K}$ at the expense of pressure drop. 
An increase in pressure drop from 291.36 $\mathrm{Pa}$ to $317.75 \mathrm{~Pa}$ is observed.

\section{- Concentration of $0.75 \%$}

There is a very high surge in pressure drop as well as in heat transfer coefficient. The pressure drop increased from 291.36 Pa to 333.17 $\mathrm{Pa}$ whereas the heat transfer coefficient increased from $32868.02 \mathrm{~W} / \mathrm{m}^{2} \mathrm{~K}$ to $35959.19 \mathrm{~W} / \mathrm{m}^{2} \mathrm{~K}$.

- Concentration of $1.0 \%$

There is very high increase in the pressure drop but the heat transfer coefficient did not increase that much as expected. The pressure drop increased from $291.36 \mathrm{~Pa}$ to $341.34 \mathrm{~Pa}$ but the heat transfer coefficient only increased from $32868.02 \mathrm{~W} / \mathrm{m}^{2} \mathrm{~K}$ to $35797.16 \mathrm{~W} / \mathrm{m}^{2} \mathrm{~K}$ which is lesser than the previous case.

- Concentration of $1.25 \%$

The value for heat transfer coefficient increased drastically from $32868.02 \mathrm{~W} / \mathrm{m}^{2} \mathrm{~K}$ to $36000.07 \mathrm{~W} / \mathrm{m}^{2} \mathrm{~K}$ which is the highest increase as compared to other cases and there is a little increase in pressure drop from 291.36 $\mathrm{Pa}$ to 332.01 $\mathrm{Pa}$ as compared to the increase in the heat transfer coefficient.

- Concentration of $1.5 \%$

There is an increase in heat transfer coefficient from $32868.02 \mathrm{~W} / \mathrm{m}^{2} \mathrm{~K}$ to $35256.38 \mathrm{~W} / \mathrm{m}^{2} \mathrm{~K}$ which is slightly lesser than the previous case and the pressure drop also increased from 291.36 $\mathrm{Pa}$ to $329.32 \mathrm{~Pa}$ which is also lesser than the previous case.

- $0.5 \%$ volume concentration of nanofluid through tubes

The heat transfer coefficient surged from 32868.02

$\mathrm{W} / \mathrm{m}^{2} \mathrm{~K}$ to $36050.38 \mathrm{~W} / \mathrm{m}^{2} \mathrm{~K}$ but the pressure drop did not increase that much as expected. The pressure drop increased only from 291.36 Pa to $306.28 \mathrm{~Pa}$ as compared to increase in heat transfer coefficient.

Case B: Study with geometric parameters

Unequal baffle spacing and reduction in number of baffles

A decrease in the pressure drop and an increase in the heat transfer coefficient are observed. The pressure drop decreased from $291.36 \mathrm{~Pa}$ to $256.45 \mathrm{~Pa}$ causing an approximate change of around $12 \%$. The heat transfer coefficient changed from $32868.02 \mathrm{~W} / \mathrm{m}^{2} \mathrm{~K}$ to 34011.91 $\mathrm{W} / \mathrm{m}^{2} \mathrm{~K}$.

- Increment in diameter of tubes

The heat transfer coefficient plunged from 32868.02 $\mathrm{W} / \mathrm{m}^{2} \mathrm{~K}$ to $16715.21 \mathrm{~W} / \mathrm{m}^{2} \mathrm{~K} \quad$ but there is very little reduction in pressure drop from 291.36 $\mathrm{Pa}$ to $289.55 \mathrm{~Pa}$.

- Reduction in number of tubes

The heat transfer coefficient increased drastically from $32868.02 \mathrm{~W} / \mathrm{m}^{2} \mathrm{~K}$ to $34338.6 \mathrm{~W} / \mathrm{m}^{2} \mathrm{~K}$ but the pressure drop increased a little from 291.36 Pa to $303.71 \mathrm{~Pa}$ comparatively.

Generally a heat exchanger is designed to obtain maximum possible heat transfer between the two fluids at the minimal expense of pressure drop between them. Hence in this study a new parameter known as heat transfer coefficient per unit length against pressure drop is plotted to explore its thermal effectiveness against the pumping power required. The new design can be incorporated in the industries which will ultimately reduce the losses and increase the efficiency of the heat exchanging devices along with reduction in the cost of generation. There are few areas where the research can be extended and one such is comparative study of the effect of multiphase fluids on heat transfer coefficient and pressure drop and the CFD results can be compared with that of the nanofluids. The other area for the extension of research is using very small volume concentrations of nanofluid $(0.01-0.1 \%)$ through the shell side of the heat exchangers.

\section{Conclusions}

1. It is observed that the optimum pressure drop is obtained with nano-particle concentration of $1 \%$.

2. The overall heat transfer coefficient increases up-to the nanoparticle concentration of $1.25 \%$ and thereafter decreases.

3. The heat transfer coefficient increases and pressure drop decreases with unequal baffle spacing.

4. Even though, the increase in tube diameter decreased the pressure drop, the Nusselt number decreases exponentially resulting in reducing the heat transfer between the fluids.

5 . The increase in number of tubes increases the heat transfer characteristics at the expense of pressure drop.

\begin{tabular}{|c|c|c|}
\hline \multicolumn{2}{|c|}{ Nomenclature } & \\
\hline $\mathrm{Al}_{2} \mathrm{O}_{3}$ & & aluminum oxide \\
\hline$b_{i}$ & - & inner diameter \\
\hline$b_{o}$ & - & outer diameter \\
\hline B & - & baffle pitch (mm) \\
\hline $\mathrm{B}_{\mathrm{c}}$ & - & baffle cut $(\%)$ \\
\hline $\mathrm{B}_{\mathrm{t}}$ & - & baffle thickness (mm) \\
\hline $\mathrm{C}$ & - & inertial resistance factor $\left(\mathrm{m}^{-1}\right)$ \\
\hline CFD & - & computational fluid dynamics \\
\hline $\mathrm{CuO}$ & - & copper oxide \\
\hline $\mathrm{C}_{\mathrm{p}}$ & - & specific heat capacity $(\mathrm{J} / \mathrm{kg}-\mathrm{K})$ \\
\hline $\mathrm{C}_{\varepsilon 1}, \mathrm{C}_{\varepsilon 2}, \mathrm{C}_{\mu}$ & - & turbulent model constants \\
\hline $\mathrm{d}_{\mathrm{i}}$ & - & diameter of inner tube $(\mathrm{mm})$ \\
\hline $\mathrm{d}_{\mathrm{o}}$ & - & diameter of outer tube (mm) \\
\hline $\mathrm{D}_{\mathrm{i}}$ & - & inner diameter of shell (mm) \\
\hline $\mathrm{D}_{\mathrm{o}}$ & - & outer diameter of shell (mm) \\
\hline FLFL & - & Fluid-Fluid interface \\
\hline FLSO & - & Fluid-Solid interface \\
\hline $\mathrm{g}$ & - & acceleration due to gravity $\left(\mathrm{m}^{2} / \mathrm{s}\right)$ \\
\hline htc & - & heat transfer coefficient $\left(\mathrm{W} / \mathrm{m}^{2} \mathrm{~K}\right)$ \\
\hline $\mathrm{k}$ & - & $\begin{array}{l}\text { turbulent fluctuations of kinetic energy } \\
\text { per unit mass }\end{array}$ \\
\hline $\mathrm{L}$ & - & length of heat exchanger (mm) \\
\hline $\mathrm{Nu}$ & - & Nusselt number \\
\hline $\mathrm{N}_{\mathrm{b}}$ & - & number of baffles \\
\hline $\mathrm{N}_{\mathrm{T}}$ & - & number of tubes \\
\hline $\mathrm{p}$ & - & tube pitch (mm) \\
\hline $\mathrm{P}$ & - & pressure $(\mathrm{Pa})$ \\
\hline $\operatorname{Pr}$ & - & Prandtl number \\
\hline q & - & heat flux as a source term $\left(\mathrm{W} / \mathrm{m}^{2}\right)$ \\
\hline $\operatorname{Re}$ & - & Reynolds number \\
\hline SOSO & - & Solid - Solid interface \\
\hline $\mathrm{T}$ & - & temperature $(\mathrm{K})$ \\
\hline TEMA & - & $\begin{array}{l}\text { tubular exchanger manufacturers } \\
\text { association }\end{array}$ \\
\hline $\mathrm{u}, \mathrm{v}, \mathrm{w}$ & - & components of velocity $(\mathrm{m} / \mathrm{s})$ \\
\hline$\overline{\mathrm{u}}$ & - & mean velocity $(\mathrm{m} / \mathrm{s})$ \\
\hline $\mathrm{x}, \mathrm{y}, \mathrm{z}$ & - & position coordinates \\
\hline Subscript & & \\
\hline $\mathrm{i}$ & - & in i-direction \\
\hline iss & - & inner cover of shell \\
\hline $\mathrm{j}$ & - & in $\mathrm{j}$-direction \\
\hline $\mathrm{nf}$ & - & nanofluid \\
\hline np & - & nanoparticle \\
\hline oss & - & outer cover of shell \\
\hline $\mathrm{w}$ & - & water \\
\hline
\end{tabular}


$\mu \quad$ dynamic viscosity (Pa s)

$\tau$ shear stress $\left(\mathrm{N} / \mathrm{m}^{2}\right)$

$\lambda$ viscosity coefficient

$\rho$ density $\left(\mathrm{kg} / \mathrm{m}^{3}\right)$

$\varnothing$ volume fraction (\%)

$\mu_{\mathrm{b}}$ dynamic viscosity at bulk temperature (Pa s)

$\mu_{\text {wall }}$ dynamic viscosity at inner tube wall temperature (Pas)

$v \quad$ kinematic viscosity $\left(\mathrm{m}^{2} / \mathrm{s}\right)$

$\nu_{\mathrm{T}} \quad$ turbulent viscosity $\left(\mathrm{m}^{2} / \mathrm{s}\right)$

$\sigma_{\mathrm{k}}, \sigma_{\varepsilon} \quad$ turbulent model constants

$\kappa \quad$ thermal conductivity $(\mathrm{W} / \mathrm{m}-\mathrm{K})$

\section{References}

[1] D. Gaddis, editor. Standards of the Tubular Exchanger Manufacturers Association, $9^{\text {th }}$ Ed. Newyork: TEMA Inc.; 2007.

[2] E. Ozden, I. Tari, "Shell side CFD analysis of a small shell-and-tube heat exchanger," Energ. Convers. Manage. 51, 1004-14, 2010.

[3] S. E. Rad, H. Afshin, B. Farhanieh, "Heat Transfer Enhancement in Shell-and-Tube Heat Exchangers Using Porous Media," Heat Transfer Eng. 36, 262-77, 2015.

[4] W. K. Kim, T. Aicher, "Experimental investigation of heat transfer in shell-and-tube heat exchangers without baffles," Korean J. Chem. Eng. 14, 93-100, 1997.

[5] M. Prithiviraj, M. J. Andrews, "Three dimensional numerical simulation of shell-and-tube heat exchangers. Part I: foundation and fluid mechanics," Numer Heat Tr A-Appl. 33, 799-816, 1998.

[6] Y. G. Lei, Y. L. He, P. Chu, R. Li, "Design and optimization of heat exchangers with helical baffles," Chem. Eng. Sci. 63, 4386-4395, 2008.

[7] H. Halle, J.M. Chenoweth, M.W. Wambsganss, "Shellside waterflow pressure drop distribution measurements in an industrial-sized test heat exchanger," J. Heat Transfer. 110, 60-67, 1988.

[8] E. S. Gaddis, V. Gnielinski, "Pressure drop on the shell side of shell-and-tube heat exchangers with segmental baffles," Chem. Eng. Process. Process Intensif. 36149159, 1997.

[9] D. Eryener, "Thermoeconomic optimization of baffle spacing for shell and tube heat exchangers," Energ. Convers. Manage. 47, 1478-1489, 2006.

[10] C. Wang, J. G. Zhu, Z. F. Sang, "Experimental studies on thermal performance and flow resistance of heat exchangers with helical baffles," Heat Transfer Eng. 30, 353-358, 2009.
[11] A. Singh, S.S. Sehgal, "Thermohydraulic Analysis of Shell-and-Tube Heat Exchanger with Segmental Baffles," ISRN Chem. Eng. 2013.

[12] V. V. P. Dubey, R. R. Verma, P. S. Verma, A. K. Srivastava, "Performance Analysis of Shell and Tube Type Heat Exchanger Under The Effect of Varied Operating Condition," IOSR Journal of Mechanical and Civil Engineering. 11, 8-17, 2014.

[13] E. M. Sparrow, L. G. Reifschneider, "Effect of interbaffle spacing on heat transfer and pressure drop in a shell-and-tube heat exchanger. Int. Heat Mass Transfer. 29, 1617-1628, 1986.

[14] Y. T. Yang, M. L. Hwang, Numerical simulation of turbulent fluid flow and heat transfer characteristics in heat exchangers fitted with porous media. Int. Heat Mass Transfer 52, 2956-2965, 2009.

[15] A. Karno, S. Ajib, "Effect of tube pitch on heat transfer in shell-and-tube heat exchangers-new simulation software," Heat Mass Transfer. 42, 263-270, 2006.

[16] R. S. Kistler, J. M. Chenoweth, "Heat exchanger shellside pressure drop: comparison of predictions with experimental data," J. Heat Transfer. 110, 68-76, 1988.

[17] T. Pekdemir, T. W. Davies, L. E. Haseler, A. D. Diaper, "Pressure drop measurements on the shell side of a cylindrical shell-and-tube heat exchanger," Heat Transfer Eng. 15, 42-56, 1994.

[18] S. Ajib, A. Karno, "Effects of baffle cut and number of haffles on pressure drop and heat transfer in shell-andtube heat exchangers-numerical simulation. Int J Heat Exchangers 7, 299-322, 2006.

[19] W. T. Sha, C. I. Yang, T. T. Kao, S. M. Cho, "Multidimensional numerical modeling of heat exchangers," J. Heat Transfer 104, 417-425, 1982.

[20] K. T. Raj, S. Ganne, "Shell side numerical analysis of a shell and tube heat exchanger considering the effects of baffle inclination angle on fluid flow using CFD," Thermal Science 16, 1165-1174, 2012.

[21] J. Albadr, S. Tayal, M. Alasadi, "Heat transfer through heat exchanger using $\mathrm{Al}_{2} \mathrm{O}_{3}$ nanofluid at different concentrations," Case Studies in Thermal Engineering. 1, 38-44, 2013.

[22] K. Y. Leong, R. Saidur, M. Khairulmaini, Z. Michael,A. Kamyar, "Heat transfer and entropy analysis of three different types of heat exchangers operated with nanofluids," Int. Commun Heat Mass. Transfer 39, 838-843, 2012. 